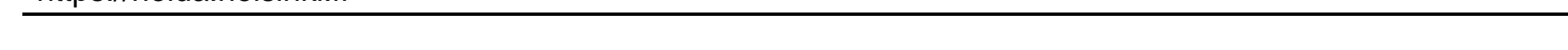

$-2$ 


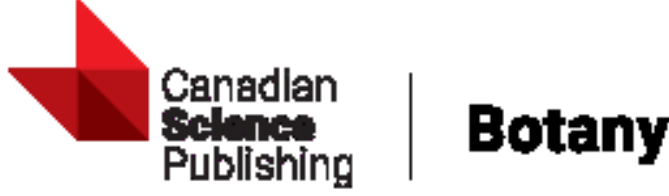

\section{Studies in Basidiodendron eyrei and similar-looking taxa (Auriculariales, Basidiomycota)}

\begin{tabular}{|c|c|}
\hline Journal: & Botany \\
\hline Manuscript ID & cjb-2020-0045.R2 \\
\hline Manuscript Type: & Article \\
\hline $\begin{array}{r}\text { Date Submitted by the } \\
\text { Author: }\end{array}$ & 14-J ul-2020 \\
\hline Complete List of Authors: & $\begin{array}{l}\text { Spirin, Viacheslav ; Botany Unit (Mycology), Finnish Museum of Natural } \\
\text { History, University of Helsinki., } \\
\text { Malysheva, Vera; Komarov Botanical Institute RAS, Laboratory of } \\
\text { Systematic and Geography of Fungi } \\
\text { Mendes Alvarenga, Renato Lúcio; Universidade Federal de Pernambuco } \\
\text { Centro de Biociencias, Micologia } \\
\text { Kotiranta, Heikki; Finnish Environment Institute } \\
\text { Larsson, Karl-Henrik; Natural History Museum , University of Oslo, }\end{array}$ \\
\hline Keyword: & heterobasidiomycetes, phylogeny, taxonomy \\
\hline $\begin{array}{r}\text { Is the invited manuscript for } \\
\text { consideration in a Special } \\
\text { Issue? : }\end{array}$ & Not applicable (regular submission) \\
\hline
\end{tabular}

\section{SCHOLARONE ${ }^{m}$ \\ Manuscripts}


Studies in Basidiodendron eyrei and similar-looking taxa (A uriculariales, B asidiomycota)

V iacheslav Spirin¹, V era M alysheva², R enato L ucio M endes-A Ivarenga ${ }^{3}$, Heikki K otiranta4, Karl-Henrik L arsson 5,6

${ }^{1}$ B otany U nit (M ycology), Finnish M useum of Natural History, U niversity of Helsinki. P.O. B ox 7, FI-00014 Helsinki, Finland. e-mail: viacheslav.spirin@ helsinki.fi

${ }^{2}$ K omarov B otanical Institute, R ussian A cademy of Sciences, Prof. Popova Str., 197376 St. Petersburg, Russia. e-mail: v_malysheva@binran.ru

${ }^{3}$ D epartamento de M icologia, Centro de Biociências, U niversidade Federal de Pernambuco, A v. da Engenharia s/n, Recife, Pernambuco, 50740-570, B razil. e-mail: renatolma@gmail.com 4Finnish Environment Institute, L atokartanonkaari 11, $00790 \mathrm{Helsinki,} \mathrm{Finland.} \mathrm{e-mail:}$ heikki.kotiranta@ymparisto.fi

${ }^{5} \mathrm{~N}$ atural History M useum, University of Oslo, P.O. B ox 1172, Blindern, 0318 Oslo, N orway. email: k.h.larsson@nhm.uio.no

${ }^{6}$ G othenburg Global B iodiversity Centre, Post B ox 461, 40530 Gothenburg, Sweden

Corresponding author: Viacheslav Spirin. B otany U nit (M ycology), Finnish M useum of $\mathrm{N}$ atural History, U niversity of Helsinki. P.O. Box 7, FI-00014 Helsinki, Finland. Phone number: +358294124415. e-mail: viacheslav.spirin@ helsinki.fi 


\begin{abstract}
A bstract
Up to the present moment, Basidiodendron luteogriseum, the generic type of Basidiodendron (A uriculariales, Basidiomycota), was treated as a synonym of B. eyrei. O ur data show they are not conspecific. The identity of other members of the B. eyrei complex, i.e. B. deminutum and B. grandinioides, is clarified based on morphological and DNA data, and ten new species are described from Eurasia, as well as from North and South A merica.
\end{abstract}

K ey words: heterobasidiomycetes, phylogeny, taxonomy 
Introduction

Basidiodendron Rick is a genus of the Auriculariales (A garicomycetes, B asidiomycota) encompassing 20 accepted species (www.mycobank.org). First introduced by Rick (1938) as monotypic, the genus was re-established by Luck-Allen (1963) for effused wood-inhabiting fungi with gloeocystidia and four-celled, longitudinally septate basidia. The most striking feature of Basidiodendron, however, is a peculiar arrangement of basidia: turgid basidial cells are located at the apices of long, sinuous hyphae covered by shields of collapsed basidia along their whole length. This trait is unique among the Auriculariales, and it allows morphological differentiation of the genus from other genera of the Auriculariales with gloeocystidia, such as Bourdotia, Ductifera, Exidiopsis s.I. etc. (L uck-A llen 1963; W ells and Raitviir 1975; W ojewoda 1982). The phylogenetic study of the Auriculariales conducted by W eiss and Oberwinkler (2001) showed five Basiodiodendron species in a single cluster, al though without statistical support. K irschner et al. (2010) described a new genus 0 vipoculum for an anamorphic fungus 0 . album which clustered with two Basidiodendron species; however, the question about monophyly of the latter genus was not addressed. Therefore, it is still uncertain if Basidiodendron as defined in morphology-based taxonomic works is monophyletic. The type species of Basidiodendron, B. luteogriseum Rick, originally described from B razil, was placed among the synonyms of the European species B. eyrei (Wakef.) L uck-A llen (W ells 1959), and this viewpoint has not been questioned. However, the identity of the latter species was interpreted in different ways (Rogers 1935; Pilát 1957; W ells 1959; L uck-Allen 1963; Lowy 1971; W ells and Raitviir 1975; W ojewoda 1982; K otiranta and Saarenoksa 2005). In particular, the taxonomic status of Basidiodendron deminutum (B ourdot) L uck-A llen, B. rimulentum (Bourdot \& Galzin) Luck-Allen, B. grandinioides (Bourdot \& Galzin) Luck-A llen and Bourdotia mucosa Bourdot $\&$ Galzin versus B. eyrei has not been satisfactorily clarified. No attempts to revise the taxonomy of $B$. eyrei s.l. with DNA methods have been performed so far. This paper presents a revision of this complex based on available type material and newly collected 
specimens from E urope, N orth and South A merica, and East A sia. In total, fourteen species are dealt with, and ten of them are introduced as new to science.

M aterial and methods

M orphological study. Type specimens and other collections from herbaria $H, O, S, L E, P C, F H$, TU, S, M G and URM were studied. Herbarium acronyms are given according to Thiers (2020). All measurements were made from microscopic slides mounted in Cotton Blue, using phase contrast and oil immersion lens (L eitz Diaplan microscope, x1250 magnification). A t least 1020 gloeocystidia and turgid basidia, and 20 - 30 basidiospores were measured per each specimen studied. The following abbreviations are used in morphological descriptions: $L$ - mean basidiospore length, W - mean basidiospore width, Q' - length / width ratio, Q - mean length / width ratio, $n$ - number of measurements per specimens measured.

M easuring basidiospores in the B. eyrei complex often finds difficulty in a variable spore shape, and, consequently, in defining of what should be considered a spore length and a spore width. Identification of the basidiospore shape "normal" to a given species / specimen starts from the study of the apiculus arrangement (phase contrast illumination and Cotton B lue as a mountant are compulsory). In some species (B. deminutum, B. grandinioides etc.), most basidiospores are ellipsoid and they possess a conventionally arranged ("regular") apiculus: it is located approximately at the top of the spore longest axis which is therefore regarded as the basidiospore length while the transversal axis represents the basidiospore width. However, some basidiospores in the same specimen may have an apiculus shifted to their ventral side ("eccentric" apiculus). In this case, the longest distance between two opposite points of the basidiospore contour is counted as a spore length, the apiculus placement notwithstanding. In turn, Basidiodendron eyrei, B. luteogriseum and other species with nearly globose basidiospores represent a different case: in most spores, the apiculus is located at the top of a shorter axis dividing a basidiospore into two almost symmetrical halves ("compressed-subglobose" basidiospores). Here this axis is 
considered a basidiospore length for all cases, including a minority of basidiospores with an eccentric apiculus.

DNA study. In total, 31 specimens were selected for DNA study (Table 1). We performed PCR directly from small fragments of dried basidiocarps without prior DNA purification using Phire Plant Direct PCR K it (Thermo Scientific, USA) according to the manufacturer's instructions. The following primers were used for both amplification and sequencing: the primers ITS1F (Gardes and Bruns 1993) and ITS4 (W hite et al. 1990) for the nrITS1-5.8S-ITS2 region, primers EF1-983F and EF1-1567R (Rehner and Buckley 2005) for a part of the tef1 region, primers JS1 (Landvik 1996) and LR5 (V ilgalys and Hester 1990) for D 1-D3 domains of nrL SU region. PCR products were purified applying the GeneJ ET Gel Extraction and DNA Cleanup M icro K it (Thermo Scientific, USA ). Sequencing was performed with an A BI model 3500 Genetic A nalyzer (A pplied B iosystems, USA). Raw data were edited and assembled in M EGA 7 (K umar et al. 2016). M olecular studies were mostly carried out at the Center for collective use of scientific equipment "Cellular and molecular technology of studying plants and fungi" (Komarov B otanical Institute, Russian A cademy of Sciences, St. Petersburg, Russia).

Phylogenetic analyses. For this study, 27 nrITS, 18 tef1 and 12 nrL SU sequences were generated (Table 1). A dditionally, $58 \mathrm{nrlTS}$ and $57 \mathrm{nrLSU}$ sequences, including the outgroup, were retrieved from GenB ank and U NITE (www.ncbi.nlm.nih.gov/genbank/; https://unite.ut.ee/). Sequences were aligned with the MAFFT version 7 web tool (http://mafft.cbrc.jp/alignment/server/). The strategy G-INS-i was selected for nrL SU and tef1 datasets, and the Q-INS-i option for nrITS dataset. A partition homogeneity test (PHT) between nrITS and tef1 datasets was performed with PA UP 4.0b10* (Swofford 2002). The PHT resulted in a $p$ value of 0.065 , indicating that no significant incongruence was detected between nrITS and tef1 datasets. Phylogenetic reconstructions were performed with $M$ aximum likelihood (M L) and Bayesian (BA) analyses. B efore the analyses, the best-fit substitution model for the alignment was estimated based on the A kaike Information Criterion (AIC) using FindM odel web 
server (http://www.hiv.lanl.gov/content/sequence/findmodel/findmodel.html). HKY model was chosen for nrlTS dataset and GTR model was chosen for nrlTS+tef1 and nrlTS+nrL SU datasets. M aximum likelihood analysis was run on RAxM L servers, v.0.9.0 (K ozlov et al. 2019) with one hundred rapid bootstrap replicates. B ayesian analyses was performed with $\mathrm{M} \mathrm{rB}$ ayes 3.2.5 software (Ronquist et al. 2012), for two independent runs, each with 5 million generations (for nrITS dataset), 4 million generations (for nrlTS +nrLSU dataset) and 7 million generations (for nrlTS+tef1 dataset), under described models and four chains with sampling every 100 generations. To check for convergence of MCM C analyses and to get estimates of the posterior distribution of parameter values Tracer v1.6 was used (Rambaut et al. 2014). We accepted the result where the ESS (Effective Sample Size) was above 200 and the PSRF (Potential Scale Reduction Factor) was close to 1. Pairwise distances between ITS and tef1 sequences were calculated using p-distance methods and M aximum Composite Likelihood model in MEGA 7 program.

Newly generated sequences have been deposited in GenB ank with accession numbers given in Table 1. Sequenced specimens treated below are marked by an asterisk.

Results

Here we define the B. eyrei complex based on comparatively short basidia (in most cases less than $12 \mathrm{R}$ long) and small (not exceeding $6 \mathrm{R}$ in a largest dimension) ellipsoid, compressedsubglobose or globose basidiospores. In a few extra-European species treated below, basidiospores may reach $8 \mathrm{R}$ in length but then they usually possess an asymmetric, eccentric apiculus. Basidiodendron caesiocinereum (Höhn. \& L itsch.) Luck-A llen s.l. has on average longer basidia (12-22 R long) and larger, globose or compressed-subglobose basidiospores (5$9 \mathrm{R}$ in diam.) bearing a very distinct, regular apiculus 1-2 R long. M oreover, basidiospores in some specimens of B. caesiociner eum are ornamented by small warts easily visible in Cotton Blue while they are smooth in B. eyrei and sibling species. 
Three datasets were prepared for the present study: (1) nrlTS + nrL SU dataset used to reconstruct a general topology of the Auriculariales, with special emphasis on Basidiodendron spp., (2) nrlTS and (3) nrlTS + tef1 datasets were limited to the Basidiodendron eyrei complex. (1) The final alignment contained 1650 characters (including gaps). The overall topologies of the $M L$ and $B I$ trees were nearly identical (Fig. 1). They placed all Basidiodendron species involved in the analyses (including a newly sequenced specimen of B. luteogriseum, the generic type) in one strongly supported clade (bs $=100, p p=1$ ). This clade was recovered as a sister lineage of the Bourdotia - D uctifera clade, in correspondence with the earlier study by W eiss $\&$ O berwinkler (2001). However, our dataset was limited to the Basidiodendron species with small- or mediumsized, asymmetric or globose spores (i.e. to the B. eyrei and B. caesiocinereum complexes) and two highly deviating nrL SU sequences of B. cinereum and B. rimosum available in GenB ank were excluded from the analyses. Therefore, the question about monophyly of the genus as defined by Luck-A llen (1963) has been left for a future study.

(2) The final alignment contained 622 characters (including gaps). The overall topologies of the $M L$ and $B I$ trees were nearly identical (Supplement) and split representatives of the $B$. eyrei into six strongly supported clades. Nine ITS sequences obtained from European, A sian and N orth A merican specimens morphologically identical to the type material of $B$. eyrei and possessing characteristic compressed-subglobose basidiospores clustered with two ITS sequences of East A sian collections (Kotiranta 26050 and Spirin 19013) having globose basidiospores with higher Q values and longer gloeocystidia. ITS sequences of both latter specimens differ from $B$. eyrei sensu typi in nine base pairs ( $1 \%$ difference). Since this genetic distance is seemingly congruous to the morphological differences, we consider it as minimal species-specific difference in the $B$. eyrei complex and introduce a new species, B. alni, based on the two aforementioned specimens. ITS sequences of four other species described or reintroduced in this study, namely B. eyrei s. typi, B. globisporum, B. grandinioides, and B. salebrosum, show smaller infraspecific variation (1-4 bp difference) than in the case of B. alni - B. eyrei, and we could not connect it with 
geographic, ecological or morphological traits. However, three morphologically highly similar specimens, all found on dry coniferous wood in subal pine forests of R ussian Far East and Canada (A Iberta) and tentatively labelled as B. olivaceum, revealed ITS sequence differences comparable with those in B. alni - B. eyrei clade (8-11 bp). This contradiction between morphological and ecological data on one side and ITS-based phylogeny on another prompted uS to produce and analyse an ITS + tef1 dataset.

(3) The final alignment contained 1185 characters (including gaps). The overall topologies of the $M L$ and $B I$ trees were nearly identical. They split the B. eyr ei complex into fourteen groups, in good accordance with morphological and ecological data, which we interpret as separate species. Sequences of B. olivaceum cluster together with a high support (Fig. 2). In general, Basidiodendron spp. produce rather insignificant basidiocarps and thus they are rarely collected by researchers. This was our reason to describe four species, B. caucasicum, B. iniquum, B. microsporum, and B. remotum, based on the type specimens only. The actual diversity in the B. eyrei complex seems to be higher than presented below. In particular, sequences of B. eyrei and B. grandinioides published by W eiss and Oberwinkler (2001) and Sotome et al. (2014) have no close matches in our dataset. Geographic, ecological and morphological traits of fourteen species treated below are briefly summarized in Table 2 .

\section{Taxonomy}

Basidiodendron alni Spirin \& V. Malysheva, sp. nov. - Fig. 3

MB 834768

Holotype. Russia. K rasnoyarsk Reg.: Evenk A utonomous Dist., Podkamennaya Tunguska, Alnus hirsuta, 8.V III.2013 Kotiranta 26050* (H 7024641, isotype - LE).

Etymology: alni (Lat.) - from Alnus, the host tree genus

B asidiocarps effused, covering a few $\mathrm{cm}$, first pruinose, smooth, arid, pale cream-coloured to greyish, then continuous, smooth, waxy or partly gelatinized, cream-coloured to pale ochraceous, 
0.03-0.05 mm thick, margin gradually thinning-out. Hyphal structure monomitic, hyphae clamped, thin- or slightly thick-walled, subicular hyphae subparallel, 2-3 R in diam., subhymenial hyphae more or less clearly ascending, 1.5-2 (-2.5) R in diam. Gloeocystidia abundant, tapering (subfusiform to bottle-shaped), normally in groups of 3-6, (26-) 29-66 (-68) x (3.2-) 3.3-6.0 (-6.1) R ( $=30 / 2)$; hyphidia not seen. B asidia-bearing hyphae slightly thickwalled, up to $35 \times 2-3$ RD basidia four-celled, (8.9-) 9.1-11.3 (-11.6) × (5.8-) 6.0-7.8 (-8.0) $R(n=24 / 2)$, senescent basidia slightly thick-walled, sterigmata up to $6 \times 1.5 R$ -

B asidiospores thin-walled or with indistinctly thickened wall, globose to compressedsubglobose, (4.0-) 4.1-5.0 (-5.1) x(4.0-) 4.2-5.0 R $(n=60 / 2), L=4.40-4.65, W=4.45-4.72$, $Q^{\prime}=0.9-1.0(-1.1), Q=0.99$, apiculus rather small, regular or slightly eccentric.

Specimens examined. Russia. K habarovsk Reg.: Solnechnyi Dist., I gdomi, Alnus hirsuta, 3.IX.2016 Spirin 10913* (H). K rasnoyarsk Reg. (holotype, see above).

Remarks. Basidiodendron alni is introduced here based on two specimens from the A sian part of R ussia, both collected from Alnus hirsuta. It is most similar to the closely related B. eyrei and differs from the latter species in having more regularly globose basidiospores, smaller basidia and longer gloeocystidia. ITS sequences of B. alni show 9 bp difference (1\%) versus B. eyrei while the single available tef1 sequence of $B$. alni differs from those of B. eyrei by 3 bp $(0.7 \%)$.

Basidiodendron caucasicum Spirin, V. M alysheva \& Kotiranta, sp. nov. - Fig. 3 M B 834770 Holotype. Russia. A dygea: M aykop Dist., Guzeripl, Pinus sylvestris, 16.IX.2003 K otiranta 22569* (H 7045100, isotype - LE).

Etymology: caucasicus (L at., adj.) - from Caucasus, the geographic area where the species was collected.

B asidiocarps effused, covering a few $\mathrm{cm}$, first reticulate, smooth, pale cream-coloured to greyish, then continuous, more or less regularly tuberculate (grandinioid), waxy or partly gelatinized, 
0.05-0.1 mm thick, margin gradually thinning-out. H yphal structure monomitic, hyphae clamped, slightly thick-walled, subicular hyphae subparallel, subhymenial hyphae ascending, 1.5-2 (-2.5) R in diam. Gloeocystidia abundant, tapering (subfusiform to bottle-shaped), (14.5-) 18-30.5 (-33) x (4.3-) 4.4-5.2 (-5.4) R ( $=10 / 1)$; hyphidia not seen. Basidia-bearing hyphae slightly thick-walled, up to $30 \times 2$ RD basidia four-celled, $(7.2-) 7.3-9.4(-9.8) \times(5.6-)$ 5.8-7.0 (-7.2) R ( $n=20 / 1$ ), senescent basidia slightly thick-walled, sterigmata up to $5 \times 1.5-2$ R- B asidiospores thin-walled, subglobose or globose, more rarely broadly ellipsoid, (3.9- ) 4.0$5.1(-5.2) \times(3.2-) 3.4-4.5 R(n=30 / 1), L=4.46, W=3.91, Q^{\prime}=(1.0-) 1.1-1.3(-1.4), Q=$ 1.15 , apiculus small, regular.

Remarks. A mong the members of B. eyrei complex distributed in E urope, only B. caucasicum and B. grandinioides produce basidiocarps with a regularly tuberculate (grandinioid) hymenophore. B asidiospores of B. caucasicum are shorter than in B. grandinioides, and they are usually subglobose or globose, versus predominantly ellipsoid basidiospores in B. grandinioides. M oreover, the latter species is seemingly restricted to angiosperms while the single specimen of B. caucasicum was collected from pine. Two other conifer-dwelling species, B. deminutum and B. globisporum, differ from B. caucasicum by completely smooth basidiocarps and differently shaped basidiospores (Fig. 3). Phylogenetically, B. caucasicum is most closely related to B. olivaceum distributed in East A sia and N orth A merica. However, genetic differences between these species are substantial, i.e. $2.1-3.4 \%$ in ITS and $15.8 \%$ in tef1 sequences.

Basidiodendron deminutum (B ourdot) Luck-Allen, Can. J. B ot. 41: 1041, 1963. - Fig. 3 W Sebacina deminuta Bourdot, C. R. A ssoc. Fr. A vancem. Sci. 45: 575, 1922. Lectotype, selected here. France. A veyron: Causse N oir, Pinus sp., 30.XI.1913 G alzin 14621 (herb. B ourdot 14923) (PC 0706687, studied) (M BT 391136). 
$=$ Bourdotia rimulenta Bourdot \& Galzin, Hymen. France: 51, 1927. Lectotype, selected here. France. A veyron: Causse Noir, P inus sp., 3.X I.1911 G alzin 10159 (herb. B ourdot 20192) (PC 0084202, studied) (M B T 391137).

B asidiocarps effused, covering a few $\mathrm{cm}$, first pruinose-reticulate, smooth, arid, pale creamcoloured to greyish, then continuous, smooth or irregularly tuberculate, waxy or partly gelatinized, pale ochraceous to brow nish, $0.02-0.05 \mathrm{~mm}$ thick, margin gradually thinning-out. Hyphal structure monomitic, hyphae clamped, slightly or distinctly thick-walled, subicular hyphae subparallel or interwoven, 2-2.5 (-3) R in diam., subhymenial hyphae more or less clearly ascending, 1.5-2 (-2.5) R in diam. Gloeocystidia abundant, tapering (subfusiform to bottle-shaped), (14.5-) 15-40 (-41) x(3.8-) 4.0-7.2 (-7.5) R $(n=38 / 5)$, solitary or rarely in groups of 2-3; hyphidia not seen. B asidia-bearing hyphae slightly thick-walled, up to $20 \times 2-3$ RD basidia four-celled, (7.2-) 7.3-9.7 (-10.0) x(5.3-) 5.6-7.2 (-7.3) R ( $n=50 / 5)$, senescent basidia slightly thick-walled, sterigmata up to $4 \times 1.5-2 \mathrm{R}$ - B asidiospores thin-walled or with indistinctly thickened wall, cylindrical to broadly ellipsoid, more rarely subglobose or cordate, (3.8-) 4.1-5.6 (-5.8) X(2.8-) 2.9-4.7 (-4.9) R $(n=150 / 5), L=4.60-4.84, W=3.16-3.91, Q^{\prime}$ $=(1.1-)$ 1.2-1.7 (-1.8), Q = 1.23-1.51, apiculus small, regular or occasionally eccentric. Specimens examined. France. A veyron: Causse N oir, P inus sp., 25.IV .1910 Galzin 5686 (herb. B ourdot 9077) (PC 0706685), 13.XI.1913 Galzin 14618 (herb. B ourdot 13720) (PC 0706684), 30.XI.1913 Galzin 14621 (herb. B ourdot 14923) (lectotype of Sebacina deminuta, see above), 3.XI.1911 Galzin 10159 (herb. B ourdot 20192) (lectotype of Bourdotia rimulenta, see above). Slovenia. Tolmin: XY Pinus mugo, 5.VI.2019 Spirin 12589* (H).

Remarks. Basidiodendron deminutum was described from the southern part of France based on several collections of which one is formally designated here as a lectotype. B asidiospores of B. deminutum are mostly ellipsoid or cylindrical, with a conventionally arranged apiculus, al though spores with an eccentric apiculus are as a rule present in the same collections. In a few specimens, spores of this kind dominate over "normal" ones but we consider this as an 
infraspecific variation. So far, B. deminutum was detected only on wood of Pinus spp. in the southern part of Europe (France and Slovenia).

The taxonomic status of Bourdotia grandinioides Bourdot $\&$ Galzin, B. mucosa Bourdot $\&$ Galzin and B. rimulenta Bourdot $\&$ Galzin was interpreted in literature in two different ways. M ost authors (Pilát 1957; W ells 1959; L uck-A llen 1963 etc.) treated them as separate species. In contrast, Ginns (1982: 54) considered B. grandinioides as a variety of Bourdotia deminuta (Bourdot) Bourdot \& Galzin (= Basidiodendron deminutum). Bourdot and Galzin (1928) made use of the hierarchical categories subspecies, variety and form and indicated these by different font style and size. In addition, subspecies names were written as full binomials (genus name abridged to the first letter) while for varieties and forms only an epithet was given, immediately following the full taxon name to which they were subordinated. In a few cases B ourdot and Galzin (1928) deviated from this pattern and the names we are dealing with here is one such case. A the end of the treatment of Bourdotia a new heading "Formes insuffisamment connues:" is introduced. Under this heading the names B. rimulenta, B. grandinioides, and B. mucosa are described. There is no explicit indication that these taxa were subordinated to $B$. deminuta, which is the last name before the heading. Unfortunately, the names of these insufficiently known taxa were printed with the "variety" font. This gives us two choices. Either to interpret the names as varieties, in which case we are left without a clear instruction to which species they are subordinate. The alternative is to regard the choice of the "variety" font as a printing error and accept the three names as species. We may get an indication of the correct solution by looking at the end of the treatment of Helicobasidium (B ourdot and Galzin 1928: 10-11). Here the same "variety" font is used for four species listed under the heading "E spèces à nous inconnues". Here it is even more clear that the authors did not intend to treat these taxa as varieties. Therefore, we consider B. grandinioides, B. mucosa, and B. rimulenta as validly described taxa at the species rank. 
Basidiodendron grandinioides is re-described below as a good species, while B. mucosa is placed among the synonyms of $B$. eyrei. The interpretation of B . rimulenta is more difficult. The species description was based on two collections, one from Pinus (Galzin 10159) and another one from Acer (Galzin 13279). W hile transferring B. rimulenta to Basidiodendron, Luck-Allen (1963) designated them both as syntypes. We re-checked these specimens and concluded they are not conspecific, the Acer-dwelling one belonging to B. eyrei (see below) and the P inusdwelling one representing $B$. deminutum. The latter collection is widely dominated by cordate basidiospores (depicted by Luck-Allen 1963: 1038), and it was seemingly the main source for the original description, as well as Luck-A llen's reintroduction of this species. N evertheless, basidiospores of the shape and size typical for other collections of B. deminutum are present too, and other microscopic characters point to B. deminutum. Therefore, we select the specimen Galzin 10159 as a lectotype of $B$. rimulenta and place the species as a synonym of $B$. deminutum.

Basidiodenron eyrei (Wakef.) Luck-A llen, Can. J. B ot. 41: 1034, 1963. - Figs. 3, 4 W Sebacina eyrei Wakef., Trans. Br. M ycol. Soc. 5: 126, 1915. Syntype. United K ingdom. England: Hampshire, A Iresford, Fagus sylvatica, 4.V .1914 Eyre (duplicate in herb. Bourdot 18464) (PC 0084215, studied). $=$ Corticium involucrum B urt, A nn. M o. Bot. Gard. 13: 271, 1926. Holotype. USA. V ermont: Addison Co., M iddlebury, on wood, 27.X I.1894 Burt (FH 00526055, studied). = Bourdotia mucosa B ourdot \& Galzin, Hyménomyc. de France (Sceaux): 51, 1927. Lectotype. France. A veyron: St. Sernin, Prunus cerasus, 9.IV .1910 Galzin 5428 (herb. B ourdot 7129) (PC 0084203, studied) (selected by W ells 1959).

B asidiocarps effused, covering a few $\mathrm{cm}$, first pruinose, arid, pale cream-coloured to greyish, then continuous, smooth, waxy or arid, cream-coloured to pale ochraceous, $0.04-0.1 \mathrm{~mm}$ thick, sometimes irregularly cracking, old basidiocarps partly gelatinized, watery-greyish to brownish, margin gradually thinning-out. Hyphal structure monomitic, hyphae clamped, subicular hyphae 
thin- or slightly thick-walled, subparallel, 1-3 R in diam., subhymenial hyphae thin-walled, interwoven or ascending, 1.5-2.5 (-3) R in diam. Gloeocystidia abundant, tapering (subfusiform to bottle-shaped), normally in groups of 3-6, (16-) 17-45 (-46) $\times(3.2-)$ 3.3-7.7 (7.8) R ( $n=50 / 5$ ); hyphidia not seen. Basidia-bearing hyphae slightly thick-walled, up to $35 x$ 2-2.5 RD basidia four-celled, (8.2-) 8.3-13.2 (-13.4) x(5.8-) 6.0-8.2 (-8.3) R ( $\mathrm{n}=130 / 7)$, senescent basidia slightly thick-walled, sterigmata up to $6 \times 1.5 \mathrm{R}$ - B asidiospores thin-walled or with indistinctly thickened wall, compressed-subglobose to almost globose, (3.7-) 3.8-5.2 ($5.4) \times(4.0-)$ 4.2-5.4 (-5.7) $R(n=330 / 11), L=4.15-4.71, W=4.66-5.14, Q^{\prime}=0.8-1.0, Q=$ 0.88-0.97, apiculus distinct to rather small, regular or eccentric.

Specimens examined. Canada. B ritish Columbia: Fraser - Fort George Reg. Dist., M t. Robson Provincial Park, Picea sp., 25.VII.2015 Spirin 8881* (A LTA, H). Estonia. Viljandimaa: Pääsma, Alnus incana, 18.IX .2018 Spirin 12363* (H, TU ). Finland. U usimaa: Helsinki, V iikki, Salix caprea, 17.V I.2008 M iettinen 12700 (H 6012551); V antaa, M ustavuori, Sorbus aucuparia, 11.V .2012 M iettinen 15359 (H 6012941). France. A veyron, Buxus sempervirens, 13.V .1913 Galzin 13342 (herb. Bourdot 13970) (PC 0706686), St. Sernin, Prunus cerasus, 9.IV .1910 Galzin 5428 (herb. B ourdot 7129) (lectotype of Bourdotia mucosa, see above), LabastidePradines, Acer sp., 13.V .1913 Galzin 13279 (herb. B ourdot 20190) (PC 0084219, as B. rimulenta). N orway. A ust-A gder: Landvik, Holvannet ved Skiftenes, Q uercus robur, 22.V III.1971 Ryvarden 8205B (O 104746). V estfold: Tønsberg, Gullkronene, F raxinus excelsior, 15.IX.2016 Spirin 11086 (0). A kershus: A sker, Stokkerelva at $\AA$ staddammen, Alnus incana, 28.IX.2018 Spirin 12433, 12435 (0); B ærum, K jaglidalen, U Imus glabra, 16.IX.2016 Spirin 11120 (0). B uskerud: Lier, Horn ved Holtsfjorden, Tilia cordata, 26.IX.1975 Ryvarden 13460 (0 104745), Stokkerinden, Acer platanoides, 29.IX.2018 Spirin 12498 (0). Hordaland: V oss, Ringheim, Corylus avellana, 18.XI.1951 Stordal 7310 (0 104747). Russia. K rasnoyarsk Reg.: Evenk A utonomous Dist., Podkamennaya Tunguska, Betula sp., 13.V III.2013 K otiranta 26231* (H). Leningrad Reg.: Podporozhie Dist., V azhinka, B etula pubescens, 16.IX.2017 Spirin 
11386 (H). Nizhny Novgorod Reg.: A rzamas Dist., Pustynsky Nat. Res., T. cordata, 12.V III.2015 Spirin 9136 (H); L ukoyanov Dist., Panzelka, T. cordata, 9.V III.2016 Spirin 10579* (H), Razino, Populus tremula, 30.V III.2019 Spirin 13060 (H), T. cordata, 8.V III.2014 Spirin 7235 (H), 23.V II.2018 Spirin 12003* (H), Q uercus robur, 6.IX.2018 Spirin $12248(H)$; Pavlovo Dist., Chudinovo, P. tremula, 15.V II.2016 Spirin 10260 (H). Spain. M álaga: Estepona, Los Reales de Sierra B ermeja, Abies pinsapo, 21.XI.2012 M iettinen 15918.2* (H). Sweden. Halland: Släp, Särö V ästerskog, 6.X .1970 E riksson (0 104741, 104749). Switzerland. B aselland: W aldenburg, Hölstein, F agus sylvatica (?), 13.VI.2009 M iettinen 13649* (H). U nited K ingdom. England: Hampshire, A Iresford, F . sylvatica, 4.V .1914 Eyre (herb. B ourdot 18464) (isosyntype of Sebacina eyrei, see above), [probably the same locality], F . sylvatica, V .1914 comm. Bresadola (herb. B ourdot 13930) (PC). USA. V ermont: A ddison Co., M iddlebury, on wood, 27.XI.1894 Burt (holotype of Corticium involucrum, see above). W ashington: J efferson Co., Port Townsend, Fort W orden, Arbutus menziesii, 9.X .2014 Spirin 8313* (H). Remarks. In almost all cases, B. eyr ei can be easily identified due to compressed-subglobose basidiospores and angiosperm hosts. It is the most common species of the complex and widely distributed in the temperate zone of Eurasia and N orth A merica. However, a few collections studied by us (including the lectotype of Bourdotia mucosa and one authentic collection of B. rimulenta) possess highly variable, predominantly ellipsoid or cordate basidiospores, (3.2-) 3.8$6.0(-6.1) \times(3.0-) 3.1-5.7(-5.8) R(n=120 / 4), L=4.51-5.05, W=3.81-4.73, Q^{\prime}=(0.6-)$ 0.7-1.6 (-1.8), $Q=0.96-1.35$ (not included in the species description above). Two of these problematic specimens were sequenced and turned out identical to the rest of B . eyrei samples. Rather long basidia and fasciculate gloeocystidia al so pointed towards the latter species. We are willing to explain their tricky spore shape and size by unusual sporulation conditions. Specimens of $B$. eyrei dominated by ellipsoid basidiospores can be confused with B. deminutum and B. grandinioides. In these cases, attention should be paid for basidia and gloeocystidia: basidia are 
smaller in the two latter species, and gloeocystidia are solitary or only rarely arranged in pairs or triads.

Basidiodendron globisporum Spirin \& V. M alysheva, sp. nov. - Figs. 3, 5 MB 834771

Holotype. Russia. Leningrad Reg.: K irishi Dist., Shariya, Picea abies, 10.VIII.2019 Spirin 12929* (H, isotype - LE).

Etymology: globisporus (Lat., adj.) - having globose spores.

B asidiocarps effused, covering a few $\mathrm{cm}$, pruinose-reticulate, smooth, waxy, first whitish, then bluish-greyish, in older parts pale ochraceous, $0.02-0.03 \mathrm{~mm}$ thick, margin gradually thinningout. Hyphal structure monomitic, hyphae clamped, subicular hyphae thin- or slightly thickwalled and subparallel, 2-3 R in diam., subhymenial hyphae very thin-walled (quickly collapsing), ascending, 1.5-2 (-2.5) R in diam. Gloeocystidia abundant, tapering (subfusiform to bottle-shaped), (12-) 15-32 (-33) x(3.0-) 3.2-6.0 (-6.2) R ( $=42 / 4)$, occasionally with a hyphoid apical outgrowth; hyphidia not seen. B asidia-bearing hyphae slightly thick-walled, up to $25 \times 2-3$ RD basidia four-celled, (7.8-) 8.8-12.0 (-12.4) x(6.8-) 7.0-9.1 (-9.3) R ( $=60 / 4)$, senescent basidia slightly thick-walled, sterigmata up to $8 \times 1.5-2 \mathrm{R}$ - B asidiospores thin-walled or with indistinctly thickened wall, compressed-subglobose to globose, (4.4-) 4.6-5.8 × (4.6-) 4.8-5.9 (-6.0) R $(n=150 / 5), L=4.95-5.15, W=5.10-5.33, Q^{\prime}=0.9-1.0(-1.1), Q=0.96-$ 0.98 , apiculus distinct to rather small, regular.

Specimens examined. Russia. Leningrad Reg.: B oksitogorsk Dist., V algozero, P icea abies, 16.V II.2014 Spirin 7040* (H), K olp', P. abies, 26-28.V II.2016 Spirin 10326*, 10396 (H); K irishi Dist. (holotype, see above). Slovenia. Gorenjska: M ojstrana, Triglavska B istrica, P. abies, 28.IX .2019 Spirin 13450* (H). Sweden. Värmland: Torsby, Fänstjärnskogen, P. abies, 9.X.2010 J . Nordén 7424 (0). USA. New Y ork: Sullivan Co., W olf Lake, Tsuga sp., 15.V III.2012 M iettinen 15584* (H). 
Remarks. Basidiodendron globisporum is morphologically most similar to B. eyrei. It differs from the latter species in having slightly larger and more globose basidiospores with a regular apiculus. Basidiodendron globisporum is distributed in temperate-boreal coniferous forests where it occurs on rotten wood of Picea abies (with one single record on Tsuga in USA ). On the contrary, B. eyrei is almost totally restricted to angiosperm hosts, and it certainly prefers forests dominated by broad-leaved trees.

Basidiodendron grandinioides (B ourdot \& Galzin) Luck-A llen, Can. J. B ot. 41: 1039, 1963. Fig. 3

W Bourdotia grandinioides B ourdot \& Galzin, Hyménomyc. de France (Sceaux): 51, 1927. Lectotype. France. A veyron: B etirac, P opulus sp., 9.V I.1910 G alzin 5522 (herb. B ourdot 20193) (PC 0084201, studied) (selected by Luck-A llen 1963).

B asidiocarps effused, covering a few $\mathrm{cm}$, first pruinose, smooth, arid, pale cream-coloured to greyish, then continuous, more or less regularly tuberculate (grandinioid), waxy or partly gelatinized, pale ochraceous to brow nish, 0.02-0.04 mm thick, margin gradually thinning-out. Hyphal structure monomitic, hyphae clamped, thin- or slightly thick-walled, subicular hyphae subparallel, 1.5-2.5 (-3) R in diam., subhymenial hyphae more or less clearly ascending, 1.5-2 (-2.5) R in diam. Gloeocystidia abundant, tapering (subfusiform to bottle-shaped), (10-) 12.5$32(-36) \times(3.7-)$ 3.8-6.6 (-6.8) R ( $=30 / 4)$; hyphidia not seen. B asidia-bearing hyphae slightly thick-walled, up to $15 \times 2-3$ RD basidia four-celled, (7.8-) 7.9-11.4 (-12.1) $\times(5.4-)$ 6.2-8.0 (-8.3) R ( $n=40 / 4)$, senescent basidia slightly thick-walled, sterigmata up to $5.5 \times 1.5$ $2 \mathrm{R}$ - B asidiospores with thin or slightly thickened (0.2-0.3 R wall, ellipsoid to broadly ellipsoid, more rarely subglobose, (3.8-) 4.0-6.0 (-6.1) x (3.0-) 3.1-4.9 (-5.0) R ( $\mathrm{n}=150 / 5)$, $\mathrm{L}=4.59-5.13, \mathrm{~W}=3.60-4.12, \mathrm{Q}^{\prime}=(1.0-) 1.1-1.5(-1.6), \mathrm{Q}=1.22-1.36$, apiculus small, regular or only in exceptional cases slightly eccentric. 
Specimens examined. France. A veyron: B etirac, Populus sp., 9.VI.1910 G alzin 5522 (herb. B ourdot 20193) (lectotype of Bourdotia grandinioides, see above). N orway. A kershus: A sker, Stokkerelva at $\AA$ staddammen, U . glabra, 5.V .2016 Spirin 10031 (0), 28.IX .2018 Spirin 12437* (O, H). N ord-Tröndelag: L evanger, Östborg, hardwood branch, 16.IX .1972 Strid 11315* (S F29104). Russia. K habarovsk Reg.: Solnechnyi Dist., Sonakh, Quercus mongolica, 15.V III.2014 Spirin $7310(\mathrm{H})$.

Remarks. Basidiodendron grandinioides is a twin species of $B$. deminutum from which it differs mainly by a grandinioid hymenophore and occurrence on angiosperm hosts. The correct host information is crucial for identification of young basidiocarps with nearly smooth hymenial surface. A nother European species with grandinioid hymenophore, B. caucasicum, possesses shorter and more globose basidiospores than in B. grandinioides. One specimen from Russian Far East (Spirin 7310) was tentatively labelled as B. grandinioides based on high morphological similarity with collections from Europe and an angiosperm host. Our attempts to sequence it failed. Therefore, the presence of B. grandinioides in East A sia should be re-confirmed. Ginns (1982) placed B. grandinioides to the synonyms of B . fulvum (M assee) Ginns. The latter species is so far known from two historical collections made in the same locality in N ew Jersey, USA. We studied one of these specimens (USA. N ew Jersey: N ewfield, rotten Magnolia, VIII.1896 Ellis \& Everhart (Fungi Columbiani \#1017, as H ydnum farinaceum var. luxurians) (H 7052960)) and concluded it cannot be identical with the Eurasian material of B. grandinioides. B asidiospores of $B$. fulvum are compressed-subglobose, more similar to $B$. eyrei than to $B$. deminutum but considerably smaller, $(2.6-)$ 2.8-3.6 $(-3.7) \times 3.2-4.2 R(n=30 / 1), L=3.18, W$ $=3.77, Q^{\prime}=(0.7-)$ 0.8-0.9, $Q=0.84$. M oreover, basidiocarps of $B$. fulvum are darker, ochraceous-brownish, and basidia are clearly smaller, 6.7-7.8 $\times 5.2-6.2 \mathrm{R}(\mathrm{n}=10 / 1)$ than in B. grandinioides.

Basidiodendron iniquum A lvarenga \& K.H. Larss., sp. nov. - Fig. 3 


\section{MB 834772}

Holotype. B razil. Rondônia: Porto V elho, Parque N atural de Porto V elho, angiosperm wood, 14.III.2012 Larsson 15469* (O, isotype - H).

Etymology: iniquus (Lat., adj.) - unequal, in reference to variable basidiospores.

B asidiocarps effused, covering a few $\mathrm{cm}$, continuous, smooth, often with irregularly scattered craters, waxy, pale cream-coloured or greyish, $0.04-0.06 \mathrm{~mm}$ thick, margin gradually thinningout. Hyphal structure monomitic, hyphae clamped, subicular hyphae scattered, thick-walled, rare, 2.5-3 $\mathrm{R}$ in diam. Gloeocystidia infrequent, arising at different levels from basidia-bearing hyphae, tapering (subfusiform to bottle-shaped), (15-) 18.5-34 (-35) × (4.4-) 4.8-8.2 (-8.8) R ( $n=20 / 1$ ); hyphidia not seen. Basidia-bearing hyphae slightly thick-walled, up to $60 \times 1.5-3 R$ hardly discernible due to tightly arranged remnants of collapsed basidia; basidia four-celled, (9.3-) 9.7-13.2 (-13.3) $\times(7.2-)$ 7.3-9.1 (-9.2) R ( $=20 / 1)$, senescent basidia slightly thickwalled, sterigmata up to $6 \times 1.5-2$ R- B asidiospores thin-walled, ellipsoid to broadly ellipsoid, rarely subglobose, $(4.6-)$ 4.9-6.2 $(-6.4) \times(4.0-) 4.1-5.2(-5.3) R(n=30 / 1), L=5.50, W=$ 4.63, $Q^{\prime}=(1.0-)$ 1.1-1.3 (-1.4), Q = 1.19, apiculus distinct, regular or eccentric.

Remarks. B asidiocarps of B. iniquum have a very peculiar hyphal arrangement: they consist of a few scattered basal hyphae producing numerous, vertically oriented, densely arranged basidiabearing hyphae. The same feature occurs al so in B. luteogriseum which differs from B. iniquum mainly in having differently shaped basidiospores. In turn, these "fishbone"-like structures are less prominent in temperate - boreal species treated here. In the latter ones, they occur mostly in senescent basidiocarps. They are often dispersed among richly branched subhymenial hyphae and thus often hardly detectable. Basidiodendron iniquum is so far known only from the type locality in the Brazilian A mazon.

Basidiodendron luteogriseum Rick, B rotéria 7: 74, 1938. - Figs. 3, 6 
Lectotype, selected here. Brazil. Rio Grande do Sul: Parecy Novo, on wood, 1935 Rick (FH 00304775, studied) (M BT 391138).

B asidiocarps effused, covering a few $\mathrm{cm}$, first pruinose, smooth, arid, pale cream-coloured to greyish, then continuous, smooth, cream-coloured to pale ochraceous, $0.05-0.1 \mathrm{~mm}$ thick, margin gradually thinning-out. Hyphal structure monomitic, hyphae clamped, subicular hyphae scattered, rare, slightly thick-walled, 1.5-2 R in diam. Gloeocystidia infrequent, usually occurring at the basal parts of basidia-bearing hyphae, tapering (subfusiform to bottle-shaped), (15-) 16-31 (-33) x(3.8-) 3.9-6.6 (-7.0) R ( $=30 / 3)$; hyphidia not seen. Basidia-bearing hyphae slightly thick-walled, up to $70 \times 2-3$ RD basidia four-celled, (7.3-) 7.8-10.0 (-10.3) $\times$ (5.8-) 5.9-8.1 (-8.4) R ( $n=30 / 2)$, senescent basidia slightly thick-walled, sterigmata up to $5 x$ 1.5 R- B asidiospores thin-walled or with indistinctly thickened wall, compressed-subglobose to globose or rarely broadly ellipsoid, 4.1-5.1 (-5.3) x 4.0-5.1 (-5.4) R $(\mathrm{n}=80 / 3), \mathrm{L}=4.55-4.75$, $W=4.65-4.84, Q^{\prime}=(0.8-)$ 0.9-1.1 (-1.2), $Q=0.94-1.03$, apiculus distinct to rather small, regular or eccentric.

Specimens examined. B razil. Pernambuco: Jaqueira, R eserva Particular do Patrimônio Natural Frei Caneca, B arragem des M oças, angiosperm wood, 20.IV .2013 Larsson 16022* (O, H). Pará: Caxiuaña, Ferreira Penna Station, angiosperm wood, 15.III.2015 Larsson 16924 (O, H, M G). Rio G rande do Sul (lectotype, see above). São Paolo: Fontes do I piranga, on wood, 16-24.I.1987 Hjortstam $16515(\mathrm{O}, \mathrm{H})$.

Remarks. Basidiodendron luteogriseum is the generic type of Basidiodendron. For a long time, it was considered a synonym of B. eyrei. How ever, our study of the type material and newly collected specimens from B razil revealed this viewpoint cannot be maintained. In addition to a clear genetic distance, B. luteogriseum can be distinguished from B. eyrei due to conspicuous, fishbone-like basidia-bearing hyphae emerging directly from subicular ones, as well as more regularly shaped, predominantly globose basidiospores with higher $Q$ values. 
Basidiodendron microsporum Spirin, V. M alysheva \& Kotiranta, sp. nov. - Fig. 3 MB 834773

Holotype. Russia. Primorie: Spassk Dist., Spassk-Dalnii, Populus sp. (decorticated branch), 23.V II.2018 Kotiranta 28653* (H, isotype - LE).

Etymology: microsporus (L at., adj.) - having small spores.

B asidiocarps effused, covering a few $\mathrm{mm}$, rarely up to $1 \mathrm{~cm}$ in widest dimension, first pruinosereticulate, greyish, then continuous, brownish, gelatinized, smooth, 0.02-0.03 mm thick, margin gradually thinning-out. Hyphal structure monomitic, hyphae clamped, tightly arranged, hardly discernible, thin- to slightly thick-walled, subicular hyphae subparallel, 1-2 R in diam., subhymenial hyphae interwoven or ascending, 1.5-2.5 R in diam. G loeocystidia abundant, clavate or tapering, (13-) 14-23 (-24) x(3.2-) 3.8-5.3 (-5.4) R $(n=20 / 1)$; hyphidia not seen. B asidia-bearing hyphae slightly thick-walled, often sinuous, up to $11 \times 2$ RD basidia fourcelled, (6.1-) 6.2-7.3 (-7.8) x (4.6-) 4.9-6.2 (-6.4) R ( $=20 / 1)$, senescent basidia slightly thick-walled, sterigmata up to $5 \times 1-1.5$ R-B asidiospores thin-walled or with indistinctly thickened wall, ellipsoid to subglobose or globose, (3.2-) 3.3-4.1 (-4.2) x (2.8-) 2.9-3.8 (-3.9) $R(n=30 / 1), L=3.79, W=3.26, Q^{\prime}=(1.0-) 1.1-1.2(-1.3), Q=1.17$, apiculus distinct to small, regular.

Remarks. Basidiodendron microsporum has the smallest basidia and basidiospores among the species treated here. Due to this feature, it can be differentiated from other species distributed in temperate - boreal forests of East A sia (B. alni, B. eyrei, B. grandinioides, B. olivaceum, B. remotum and $\mathrm{B}$. salebrosum). Basidiodendron microsporum is so far known only from the type locality in Russian Far East.

Basidiodendron olivaceum Spirin \& V. Malysheva, sp. nov. - Fig. 3 MB 834774 
Holotype. Russia. K habarovsk Reg.: Solnechnyi Dist., Razlivnaya, Pinus pumila, 23.V III.2011 Spirin 4304* $(H$, isotype - LE).

Etymology: olivaceus (Lat., adj.) - olivaceous.

B asidiocarps effused, covering a few $\mathrm{mm}$, rarely up to $1 \mathrm{~cm}$ in widest dimension, first pruinosereticulate, smooth, arid, ochraceous, then continuous, irregularly tuberculate, arid or only slightly gelatinized, dirty ochraceous to pale olivaceous-brown, 0.02-0.05 mm thick, margin gradually thinning-out. Hyphal structure monomitic, hyphae clamped, tightly arranged, thin- to slightly thick-walled, subicular hyphae interwoven, 2-3 R in diam., subhymenial hyphae interwoven or ascending, 1.5-2.5 (-3) R in diam. Gloeocystidia abundant, clavate or indistinctly tapering, (12-) 13-22 (-24) x (4.0-) 4.7-7.3 (-7.4) R ( $\mathrm{n}=30 / 3)$, contents dark brown; hyphidia rarely present, simple or bifurcate, 1-1.5 R in diam. at the apex. B asidia-bearing hyphae slightly thick-walled, hardly discernible, up to $30 \times 2-3$ RD basidia four-celled, (6.4-) 6.8-9.1 (-9.2) $\times$ (5.1-) 5.3-7.1 (-7.7) R ( $n=38 / 4)$, senescent basidia slightly thick-walled, sterigmata up to $7 \times$ 1.5-2 R- B asidiospores thin-walled or with indistinctly thickened wall, ellipsoid to subglobose or globose, (3.3-) 3.4-5.1 (-5.2) x(2.8-) 2.9-4.7 R $(n=120 / 4), L=3.99-4.51, W=3.29$ $4.06, Q^{\prime}=(1.0-)$ 1.1-1.4 (-1.5), Q = 1.11-1.22, apiculus distinct to small, regular or eccentric. Specimens examined. Canada. A Iberta: Y ellowhead Co., W hitehorse W ildland Provincial Park, Picea glauca, 26.V II.2015 Spirin 8969* (A LTA, H). Russia. K habarovsk Reg.: Solnechnyi Dist., Igdomi, Pinus pumila, 2.IX .2016 Spirin 10780* (H), Larix gmelinii, 6.IX .2016 Spirin 11014* (H), Razlivnaya (holotype, see above).

Remarks. Basidiodendron olivaceum is a sibling species of $B$. deminutum distributed in mountain coniferous forests of East A sia and N orth A merica. It differs from the European B. deminutum in having darker basidiocarps and shorter gloeocystidia with intensively coloured (resinous-brown) and strongly cyanophilous contents. B asidiospores of B. olivaceum are on average shorter and broader than in B. deminutum but these differences are merely statistical. So 
far, B. olivaceum was detected on fallen but tough logs and branches of conifers (Larix, Picea, Pinus).

Basidiodendron parile Spirin \& V. M alysheva, sp. nov. - Fig. 3

MB 834775

Holotype. Norway. M øre og Romsdal: Nesset, Eikesdalen, U Imus glabra, 27.IX.2017 Spirin 11607* (O, isotypes - H, LE).

Etymology: parilis (Lat., adj.) - equal, in reference to a regular basidiospore shape.

Basidiocarps effused, covering a few mm, pruinose-reticulate, smooth, waxy, greyish, 0.02-0.04 mm thick, margin gradually thinning-out. Hyphal structure monomitic, hyphae clamped, subicular hyphae thin- or slightly thick-walled and subparallel, 1-2 R in diam., subhymenial hyphae thin- or slightly thick-walled, ascending or interwoven, 1-2 (-2.5) R in diam. Gloeocystidia abundant, tapering, solitary or in groups of 2-3, (12-) 14-39 (-42) x (4.8-) 4.9$7.3(-7.8)$ R ( $n=27 / 2$ ); hyphidia not seen. B asidia-bearing hyphae slightly thick-walled, up to

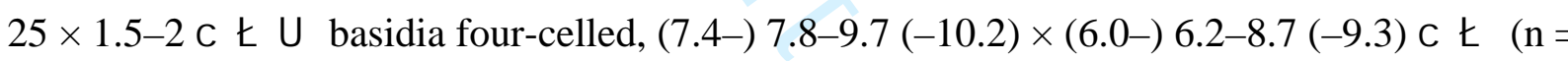
senescent basidia slightly thick-walled, sterigmata up to $5 \times 1.2-2 \mathrm{R}$ - B asidiospores thin-walled or with indistinctly thickened wall, subglobose to globose, very rarely broadly ellipsoid, (4.2-) 4.7-5.9 (-6.1) $\times(4.0-)$ 4.1-5.6 (-5.9) $R(n=60 / 2), L=5.19-5.27, W=4.97-5.02, Q^{\prime}=1.0-$ $1.1(-1.3), Q=1.03-1.06$, apiculus distinct to rather small, regular or eccentric.

Specimens examined. Norway. V estfold: Larvik, K velde, Jordstøyp, U . glabra, 15.IX.2016 Spirin 11099* (0). M øre og Romsdal (holotype, see above).

Remarks. Basidiodendron parile is introduced here based on two collections from N orway, both from very rotten wood of U Imus glabra. M orphologically, it is most close to B. globisporum which, however, occurs on coniferous hosts. In addition to substrates, these species can be separated due to different shape and size of basidiospores (Fig. 4). M oreover, basidia of B. parile are considerably smaller than in B. globisporum. 
Basidiodendron pelinum A Ivarenga \& K.H. Larss., sp. nov. - Fig. 3

MB 834776

Holotype. B razil. Pernambuco: Jaqueira, Reserva Particular do Patrimônio Natural Frei Caneca, B arragem des M oças, angiosperm wood, 20.IV .2013 Larsson 16014* (0, isotype - H). Etymology: pelinos (Gr., adj.) - clay-coloured.

B asidiocarps effused, covering a few $\mathrm{cm}$, first pruinose, then continuous, smooth or irregularly tuberculate, arid, pale ochraceous to greyish, 0.05-0.1 mm thick, in oldest parts unevenly cracking, margin gradually thinning-out. Hyphal structure monomitic, hyphae clamped, subicular hyphae slightly thick-walled, subparallel, 3-3.5 R in diam., subhymenial hyphae thin- or slightly thick-walled, interwoven, 2-3 (-3.5) R in diam. Gloeocystidia abundant, broadly clavate or tapering, (15-) 17-30 (-35) x(5.6-) 5.7-9.6 (-10.0) R $(n=30 / 2)$; hyphidia not seen. B asidia-bearing hyphae thin-walled, often strongly reduced and thus hardly discernible, occasionally distinct, up to $10 \times 2-3.5$ RD basidia four-celled, $(9.2-)$ 9.4-13.8 (-14.2) $\times(6.2-)$ 6.5-8.4 (-8.7) R ( $n=30 / 2)$, senescent basidia slightly thick-walled, sterigmata up to $8 \times 2-3$ R- B asidiospores thin-walled, broadly ellipsoid to ellipsoid-ovoid, (4.6-) 4.9-7.1 (-7.8) × (3.8) $3.9-5.2(-5.3) R(n=60 / 2), L=5.61-6.06, W=4.32-4.56, Q^{\prime}=(1.1-) 1.2-1.4(-1.5), Q=$ 1.30-1.33, apiculus distinct, regular or more rarely eccentric.

Specimens examined. Brazil. Pernambuco: J aqueira, Reserva Particular do Patrimônio Natural Frei Caneca, B arragem des M oças, angiosperm wood, 20.IV .2013 Larsson 15985 (O, H), Larsson 16014* (holotype, see above).

Remarks. Basidiodendron pelinum is introduced here based on two collections from Pernambuco, B razil. In contrast to two other species treated here, B. iniquum and B. luteogriseum, B. pelinum does not produce so pronounced fishbone-like basidia-bearing hyphae, i.e. it is anatomically more similar to temperate - boreal species of the B. eyr ei complex. 
B asidiospores of B . pelinum are regularly shaped, ellipsoid, as a rule with a conventionally placed apiculus.

Basidiodendron remotum Spirin, V. M alysheva \& K otiranta, sp. nov. - Fig. 3 M B 834777 Holotype. Russia. Y akutia: Namsky Dist., Sielyakh, Picea sp., 18.V III.1999 K otiranta 16308* (H 7039169, isotype - LE).

Etymology: remotus (Lat., adj.) - remote.

B asidiocarps effused, covering a few $\mathrm{cm}$, first pruinose-reticulate, then continuous, smooth, waxy, greyish, 0.02-0.04 mm thick, margin gradually thinning-out. Hyphal structure monomitic, hyphae clamped, subicular hyphae slightly or distinctly thick-walled, subparallel, 1.5-2.5 R in diam., subhymenial hyphae thin- or slightly thick-walled, interwoven or ascending, 1-2 R in diam. Gloeocystidia abundant, tapering or clavate, some sinuous, occasionally pleural, (18-) 19$30(-31) \times(5.3-) 5.4-8.2(-10.0)$ R $(n=20 / 1)$; hyphidia not seen. B asidia-bearing hyphae slightly thick-walled, up to $25 \times 2-2.5$ RD basidia four-celled, $(6.3-) 7.2-8.9(-9.1) \times(5.2-)$ 5.3-6.6 (-6.8) R ( $=20 / 1$ ), sterigmata up to $4 \times 1-1.5 R$ - Basidiospores with slightly thickened wall (ca. 0.2 R compressed-ellipsoid to subglobose or rarely globose, (2.9-) 3.0-3.9 $(-4.1) \times(3.6-) 3.7-4.4(-4.6) R(n=30 / 1), L=3.43, W=4.10, Q^{\prime}=0.7-0.9(-1.0), Q=0.84$, apiculus distinct to small, often asymmetric, regular or eccentric.

Remarks. Predominantly compressed basidiospores of $B$. remotum are reminiscent of those of $B$. eyrei although they are clearly larger in the latter species. So far, B. remotum is known from a single locality in Siberia where it was collected on rotten wood of spruce.

Basidiodendron salebrosum Spirin \& V. M alysheva, sp. nov. - Fig. 3 MB 834778 
Holotype. Russia. K habarovsk Reg.: K habarovsk Dist., M alyi Niran, Picea ajanensis, 7.V III.2012 Spirin 5024* (H 7022939, isotype - LE).

Etymology: salebrosus (Lat., adj.) - uneven, rough.

B asidiocarps effused, covering a few $\mathrm{cm}$, first pruinose-reticulate, then continuous, smooth, waxy or arid, greyish to pale ochraceous, $0.02-0.04 \mathrm{~mm}$ thick, margin gradually thinning-out. Hyphal structure monomitic, hyphae clamped, tightly arranged, thin-walled, subicular hyphae subparallel, 1.5-2 R in diam., subhymenial hyphae interwoven or ascending, 2-2.5 R in diam. Gloeocystidia abundant, distinctly tapering (bottle-shaped), (13-) 15-27.5 (-34) x (4.0-) 4.8-8.8 (-9.0) R ( $n=22 / 2)$; hyphidia not seen. B asidia-bearing hyphae thin-walled, often strongly reduced and thus hardly discernible, but occasionally distinct, up to $15 \times 3-4$ RD basidia fourcelled, (9.3-) 10.3-14.2 (-15.1) × (6.9-) 7.1-9.8 (-10.2) R ( $n=30 / 2)$, sterigmata up to $8 \times 1.5-$ 2 R- B asidiospores thin-walled or with indistinctly thickened wall, ellipsoid to subglobose, (5.6-) 5.7-7.6 (-8.2) $\times(4.4-)$ 4.8-6.1 (-6.4) $R(n=50 / 2), L=6.49-6.68, W=5.44-5.48, Q^{\prime}=$ 1.1-1.4 (-1.5), Q = 1.19-1.23, apiculus distinct to small, often asymmetric, regular or eccentric. Specimens examined. Russia. K habarovsk Reg.: K habarovsk Dist. (holotype, see above); Solnechnyi Dist., Igdomi, P. ajanensis, 3.IX.2016 Spirin 10900* (H).

Remarks. Large, ellipsoid or subglobose basidiospores with an asymmetric apiculus differentiate B. salebrosum from other species dealt with above, as well as from B. caesiocinereum s.I. The species was found twice in R ussian Far E ast, and both records were from decorticated but rather tough spruce logs.

Key for globose- or ellipsoid-spored Basidiodendron species in temperate - boreal Eurasia (only species with basidiospores under $8 \mathrm{R}$ in largest dimension are treated)

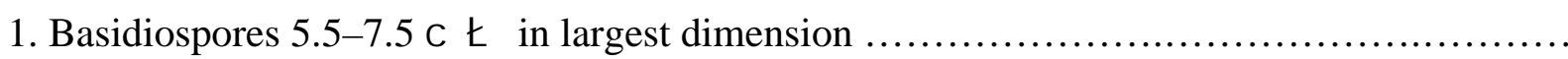

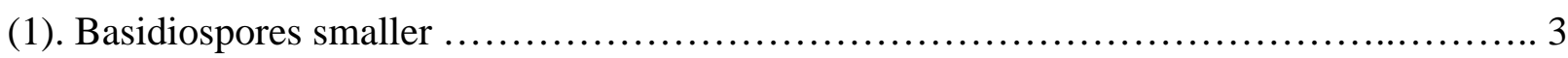


2. B asidiospores ellipsoid to subglobose, smooth. E ast $A$ sian species B. salebrosum

(2). B asidiospores globose or compressed-subglobose, sometimes warted

B. caesiocinereum s.l.

3. B asidiospores compressed-subglobose to globose 4

(3). At least some basidiospores ellipsoid or broadly ellipsoid 6

4. On conifers. A piculus regular B. globisporum

(4). On angiosperms. A piculus of some spores eccentric, asymmetric 5

5. Basidia up to $11.5 \mathrm{R}$ long, gloeocystidia up to $65 \mathrm{R}$ long, basidiospores more or less regularly subglobose or globose. East A sian species B. alni

(5). B asidia up to $13.5 \mathrm{R}$ long, gloeocystidia up to $45 \mathrm{R}$ long, at least some basidiospores clearly compressed B. eyrei

6. Basidia up to $13.5 \mathrm{R}$ long, apiculus mostly eccentric B. eyrei

(6). B asidia up to $9.5 \mathrm{R}$ long, apiculus regular or eccentric 7

7. On conifers .8

(7). On angiosperms 11

8. Europe and Caucasus .... 9

(8). East A sia and North A merica 10

9. Hymenophore grandinioid, basidiospores predominantly subglobose or globose

B. caucasicum

(9). Hymenophore smooth, basidiospores predominantly cylindrical or ellipsoid B. deminutum

10. Basidiospores compressed-ellipsoid or subglobose to globose, 3-4 × 3.5-4.5 R B. remotum

(10). B asidiospores ellipsoid to subglobose, 3.5-5 × 3-4.5 R B. olivaceum

11. Hymenophore grandinioid 12

(11). Hymenophore smooth 13 
12. B asidiospores compressed-subglobose, 3-3.7 × 3.2-4 R- N orth A merica B. fulvum

(12). B asidiospores mostly ellipsoid, 4-6 × 3-5 R- Eurasia

B. grandinioides

13. Basidiospores 4.5-6 $\times$ 4-5.5 R- Europe B. parile

(13). B asidiospores 3.5-4 × 3-4 R- East A sia B. microsporum

\section{A cknowledgements}

The curators of herbaria S, PC, FH, TU are thanked for providing specimens for loan. Otto M iettinen (University of Helsinki, Finland) kindly shared with us his collections and data. Tine Grebenc (Slovenian Forestry Institute) arranged field trips of the author V S in Slovenia. The research was supported by Norwegian Biodiversity Information Centre (the project "A survey of Norwegian jelly fungi", grant number knr. 44-15) (the authors K HL and VS), Komarov B otanical Institute, Russian A cademy of Sciences (project A A A A-A 19-119020890079-6) (the author V M ), Conselho Nacional de Desenvolvimento Científifico e Tecnológico (CN Pq 307601/2015-3) and Coordenação de A perfeiçoamento de Pessoal de Nível Superior(CA PES Capes-SIU 008/13) (the author RLM A).

\section{References}

B ourdot, H., and Galzin, A. 1927. Hyménomycètes de France. Hetérobasidiés - Homobasidiés gymnocarpes. Sceaux.

Gardes, M ., and Bruns, T.D. 1993. ITS primers with enhanced specificity for basidiomycetes applications to the identification of mycorrhizae and rusts. M ol. Ecol., 2: 113-118.

Ginns, J. 1982. A monograph of the genus Coniophora (A phyllophorales, B asidiomycetes). Opera B otanica, 61: 1-61.

K irschner, R., Y ang, Z.L., Zhao, Q., and Feng, B . 2010. O vipoculum album, a new anamorph with gelatinous cupulate bulbilliferous conidiomata from China and with affinities to the A uriculariales (B asidiomycota). Fungal Divers., 43: 55-65. 
Kotiranta, H., and Saarenoksa, R. 2005. The genus Basidiodendron (Heterobasidiomycetes, Tremellales) in Finland. A nn. B ot. Fenn., 42: 11-22.

K ozlov, A. M ., Darriba, D., Flouri, T., M orel, B ., and Stamatakis, A . 2019. RA xM L-N G: A fast, scalable, and user-friendly tool for maximum likelihood phylogenetic inference. Bioinformatics, 35 (21): 4453-4455. doi:10.1093/bioinformatics/btz305.

K umar, S., Stecher, G., and Tamura, K. 2016. M EG A 7: M olecular evolutionary genetics analysis version 7.0 for bigger datasets. M ol. Biol. Evol., 33: 1870-1874.

Lowy, B. 1971. Tremellaceae. Flora N eotropica, 6: 1-153.

Luck-A llen, R. 1963. The genus Basidiodendron. Can. J. B ot., 41: 1025-1052.

Pilát, A . 1957. Ü bersicht der europäischen A uriculariales und Tremellales unter besonderer B erücksichtigung der tschechoslowakischen A rten. A cta M usei Nationalis Pragae, 13B: 115210.

Rambaut, A ., Suchard, M .A., Xie, D., and Drummond, A .J ., 2014. Tracer v1.6. http://tree.bio.ed.ac.uk/software/tracer/ (accessed on 20.1.2020).

Rehner, S.A., and Buckley, E. 2005. A B eauveria phylogeny inferred from nuclear ITS and EF1alpha sequences: evidence for cryptic diversification and links to Cordyceps teleomorphs. M ycologia, 97: 84-98.

Rick, S.J . 1938. Resupinati Riograndenses. Brotéria, 7: 74.

Rogers, D.P. 1935. Notes on the lower Basidiomycetes. Univ. Iowa Stud. N at. Hist., 17: 37-43. Ronquist, F., Teslenko, M ., van der M ark, P., A yres, D.L., Darling, A., Höhna, S., et al. 2012. M rB ayes 3.2: efficient B ayesian phylogenetic inference and model choice across a large model space. Syst. Biol., 61: 539-542.

Sotome, K., M aekawa, N., N akagiri, A ., L ee, S.S., and Hattori, T. 2014. Taxonomic study of A sian species of poroid A uriculariales. M ycol. Prog., 13: 987-997.

Swofford DL. 2002. PA U P*: Phylogenetic analysis using parsimony (*and other methods), V ersion 4. Sinauer A ssociates, Sunderland, MA. 
Thiers, B. 2020. Index Herbariorum: a global directory of public herbaria and associated stuff 









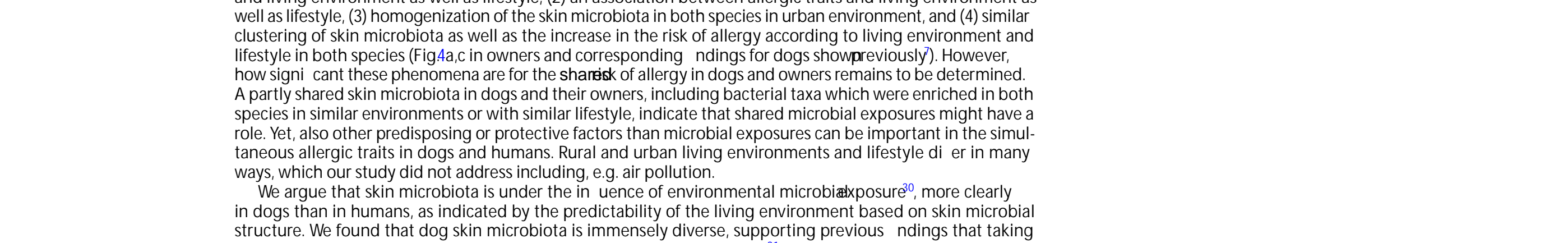



